\title{
Spotlight on grazoprevir-elbasvir once-daily combination and its potential in the treatment of hepatitis $C$
}

This article was published in the following Dove Press journal:

Drug Design, Development and Therapy

29 June 2016

Number of times this article has been viewed

\author{
Duminda Suraweera' \\ Ashley N Weeratunga ${ }^{2}$ \\ Sammy Saab ${ }^{3}$ \\ 'Department of Medicine, Olive- \\ View Medical Center, Sylmar, CA, \\ 2Department of Medicine, Creighton \\ University School of Medicine, \\ Omaha, NE, ${ }^{3}$ Department of Medicine, \\ University of California at Los \\ Angeles, Los Angeles, CA, USA
}

\begin{abstract}
Chronic hepatitis $\mathrm{C}$ virus (HCV) infection is a leading cause of health care utilization in the USA. Incidence of cirrhosis from HCV is expected to rise in the near future, further increasing this burden. There is a high medical need for effective, tolerable, safe, alloral, short-duration therapy. To this end, several new direct-acting antiviral agents have been developed and have shown excellent sustained virologic response rates. However, patients who have previously failed treatment or who have developed cirrhosis, renal failure, or human immunodeficiency virus coinfection remain difficult-to-treat subgroups. An all-oral agent that is effective in many of these subgroups would simplify treatment of HCV greatly. Here we review currently available data on the efficacy, treatment duration, tolerability, and safety of combination of grazoprevir and elbasvir.
\end{abstract}

Keywords: hepatitis C, antiviral therapy, grazoprevir, elbasvir

\section{Introduction}

Hepatitis $\mathrm{C}$ virus (HCV) infects an estimated 4-7 million people in the USA. ${ }^{1}$ Hepatitis $\mathrm{C}$ management is a burden on health care, with $\mathrm{HCV}$ being the most common indication for liver transplantation in the USA. ${ }^{2}$ Furthermore, the number of individuals infected with $\mathrm{HCV}$ who have cirrhosis in the USA is expected to rise in the future, with a peak projected between 6,00,000 and 1 million in the period between 2015 and $2020{ }^{2,3}$ Initial treatment options were limited to pegylated interferon and ribavirin. This regimen had sustained virologic response (SVR) rates, approximately $45 \%-55 \%$ at 12 weeks posttreatment. ${ }^{4-6}$ In some populations, such as the elderly and African-American patients coinfected with human immunodeficiency virus (HIV), the SVR was even lower. ${ }^{7-9}$ Furthermore, both pegylated interferon and ribavirin had high incidences of adverse events such as depression, hemolysis, pancytopenia, and live decompensation.

The introduction of direct-acting antiviral agents has revolutionized the treatment of patients infected with HCV. These new agents have resulted in dramatically improved SVR rates when compared to the previous standard of pegylated interferon and ribavirin. ${ }^{10,11}$ Previous studies have confirmed that attaining virologic cure using pegylated interferon-based therapy has resulted in significant benefits in liver-related complications and even other HCV-associated disorders such as insulin resistance. ${ }^{12-16}$ Several all-oral, direct-acting agent regimens are now available for use.

The combination of grazoprevir and elbasvir is an all-oral, direct-acting agent regimen currently being investigated for the treatment of HCV (Table 1). Grazoprevir
Correspondence: Sammy Saab Department of Medicine, Pfleger Liver Institute, UCLA Medical Center, 200 Medical Plaza, Suite 214, Los Angeles, CA 90095 , USA

Tel +I 3102066705

Fax +I 3102064197

Email ssaab@mednet.ucla.edu
Drug Design, Development and Therapy 2016:10 2119-2/27 Dovepress http://dx.doi.org/10.2147/DDDT.S90537 (c) (1) \&) 2016 Surawera et al. This work is published and licensed by Dove Medical Press Limited. The full terms of this license are available at hitps://www.dovepress.com/terms.php

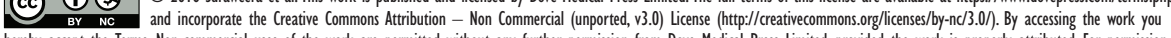
hereby accept the Terms. Non-commercial uses of the work are permitted without any further permisision from Dove Medical Press Limited, provided the work is properly attributed. For permission for commercial use of this work, please see paragraphs 4.2 and 5 of our Terms (htpps//www.dovepress.com/terms.php). 
Table I Summary of SVRI2 results from major clinical trials evaluating grazoprevir-elbasvir in treating HCV infection

\begin{tabular}{|c|c|c|c|c|c|c|c|c|}
\hline Study & Phase & Regimen & $\begin{array}{l}\text { Treatment } \\
\text { naïve }\end{array}$ & $\begin{array}{l}\text { Treatment } \\
\text { failed }\end{array}$ & Cirrhosis & ESRD & $\begin{array}{l}\text { HIV } \\
\text { coinfection }\end{array}$ & Non-GT I \\
\hline \multirow[t]{8}{*}{ Lawitz et al ${ }^{17}$} & II & $\mathrm{GE}(+\mathrm{R})$ & $28 / 31$ (90\%) & $30 / 32(94 \%)$ & $28 / 31$ (90\%) & NA & NA & NA \\
\hline & & 12 weeks & & & & & & \\
\hline & & GE $(-R)$ & $28 / 29$ (97\%) & $30 / 33$ (91\%) & $28 / 29(97 \%)$ & NA & NA & NA \\
\hline & & 12 weeks & & & & & & \\
\hline & & $\mathrm{GE}(+\mathrm{R})$ & $31 / 32$ (97\%) & $33 / 33(100 \%)$ & $12 / 12$ (100\%) & NA & NA & NA \\
\hline & & 18 weeks & & & & & & \\
\hline & & GE $(-R)$ & $29 / 31$ (94\%) & $31 / 32$ (97\%) & II/II (100\%) & NA & NA & NA \\
\hline & & 18 weeks & & & & & & \\
\hline \multirow[t]{6}{*}{ Sulkowski et al ${ }^{18}$} & II & $\mathrm{GE}(+\mathrm{R})$ & $24 / 30(80 \%)$ & NA & NA & NA & NA & NA \\
\hline & & 8 weeks & & & & & & \\
\hline & & $\mathrm{GE}(+\mathrm{R})$ & $79 / 85$ (93\%) & NA & NA & NA & $28 / 29(97 \%)$ & NA \\
\hline & & 12 weeks & & & & & & \\
\hline & & GE $(-R)$ & $43 / 44$ (98\%) & NA & NA & NA & $26 / 30(87 \%)$ & NA \\
\hline & & 12 weeks & & & & & & \\
\hline \multirow[t]{2}{*}{ Zeuzem et al ${ }^{19}$} & III & GE (-R) & |44/I 57 (95\%) & NA & $68 / 70(97 \%)$ & NA & NA & GT4 I8//8 (I00\%) \\
\hline & & 12 weeks & & & & & & GT6 8/I0 (80\%) \\
\hline Buti et $\mathrm{al}^{20}$ and & II & $\mathrm{GE}(+\mathrm{R})$ & NA & $76 / 79$ (96\%) & $32 / 34(94 \%)$ & NA & NA & NA \\
\hline Forns et $\mathrm{a}^{21}$ & & 12 weeks & & & & & & \\
\hline \multirow[t]{2}{*}{ Roth et $\mathrm{al}^{23}$} & III & GE $(-R)$ & $96 / 96(100 \%)$ & $19 / 20$ (95\%) & $6 / 6(100 \%)$ & II5/II 6 (99\%) & NA & NA \\
\hline & & 12 weeks & & & & & & \\
\hline \multirow[t]{2}{*}{ Rockstroh et $\mathrm{a}^{26}$} & III & GE $(+R)$ & $210 / 218(96 \%)$ & NA & $35 / 35(100 \%)$ & NA & $210 / 218$ (96\%) & GT4 27/28 (96\%) \\
\hline & & 12 weeks & & & & & & GT6 I/I (100\%) \\
\hline
\end{tabular}

Note: Data is presented as $\mathrm{n}(\%)$.

Abbreviations: ESRD, end-stage renal disease; GE $(+R)$, grazoprevir-elbasvir plus ribavirin; GE (-R), grazoprevir-elbasvir without ribavirin; GT, genotype; HCV, hepatitis $C$ virus; HIV, human immunodeficiency virus; NA, not applicable; SVRI2, sustained virologic response 12 weeks posttreatment.

is an NS3/4A protease inhibitor, while elbasvir is a potent NS5A inhibitor. Several Phase II and III studies have shown grazoprevir and elbasvir to be effective in previously difficult-to-treat subgroups, such as patients with cirrhosis (Child-Pugh A), previous treatment failures (null responders), coinfection with HIV, non-genotype 1, and advanced chronic kidney disease. Here we review currently available data on the efficacy, treatment duration, tolerability, and safety of grazoprevir plus elbasvir.

\section{Treatment-naïve patients}

The use of grazoprevir and elbasvir on treatment-naïve patients has been studied in three separate clinical trials. Lawitz et al ${ }^{17}$ conducted a randomized, open-label, Phase II trial (C-WORTHY) evaluating the efficacy of grazoprevir and elbasvir with and without ribavirin in patients with $\mathrm{HCV}$ genotype 1 who had not been previously treated for cirrhosis, as well as in patients who had previously failed pegylated interferon and ribavirin with or without cirrhosis. A total of 253 patients were involved in the study, of which 123 were treatment-naïve patients. This cohort was further divided into a 12-week course ( $n=60)$ and an 18-week course $(n=63)$. Approximately half of the patients received ribavirin $(n=64)$. SVR at 12 weeks posttreatment (SVR12) was achieved in
$90 \%$ (28/31 patients) who underwent the 12-week regimen with ribavirin, compared to $97 \%$ (28/29 patients) without ribavirin. When treated for 18 weeks, SVR12 of $97 \%$ (31/32 patients) was achieved with ribavirin, compared to $94 \%$ (29/31 patients) without ribavirin. There was no significant benefit in the addition of ribavirin or extension of therapy to 18 weeks.

High SVR rates in treatment-naïve patients were again demonstrated in a follow-up study to the C-WORTHY trial. Sulkowski et $\mathrm{al}^{18}$ conducted a randomized, open-label, Phase II trial evaluating the efficacy of grazoprevir and elbasvir with or without ribavirin in the treatment of patients with untreated HCV genotype 1 monoinfection and patients with untreated $\mathrm{HIV} / \mathrm{HCV}$ coinfection without cirrhosis. A total of 218 patients were included in the study, of which 159 patients had HCV monoinfection. SVR12 was achieved in 93\% (79/85 patients) when treated for 12 weeks with ribavirin, as compared to $98 \%$ (43/44 patients) without ribavirin. There was no significant difference in SVR12 between genotypes $1 \mathrm{a}$ and $1 \mathrm{~b}$. Patients with genotype 1a who were treated for 8 weeks with ribavirin achieved an SVR12 of 80\% (24/30 patients).

The efficacy of grazoprevir and elbasvir on treatmentnaïve patients with different HCV genotypes has also been evaluated. Zeuzem et $\mathrm{al}^{19}$ found similar high SVR12 in 
treatment-naïve patients, regardless of the genotype. The C-EDGE trial was a randomized, blinded, placebo-controlled, Phase III trial looking at the efficacy of grazoprevir-elbasvir combination therapy in the treatment of previously untreated HCV genotype 1, 4, or 6 infection. A total of 421 patients with and without cirrhosis were treated for a 12-week course; no ribavirin was used in this study. Three hundred and sixteen patients received grazoprevir and elbasvir, while 105 received placebo. In the active treatment group, SVR12 was achieved in $95 \%(144 / 157)$ of patients. Further subgroup analysis by genotype showed an SVR12 of 92\% (144/157 patients) in genotype 1a, 99\% (129/131 patients) in genotype 1b, 100\% (18/18 patients) in genotype 4 , and $80 \%$ (8/10 patients) in genotype 6. Patients with cirrhosis achieved an SVR12 of $97 \%$ (68/70 patients), compared to $94 \%$ (231/246 patients) of noncirrhotic patients.

The above three studies showed high SVR rates with grazoprevir-elbasvir combination. There was no significant difference in SVR in treatment-naïve patients with cirrhosis, when compared to those without cirrhosis. HCV genotype did not affect SVR rates in one study. Furthermore, the use of ribavirin did not lead to increased SVR in treatment-naïve patients. Lastly, a course of 12 weeks seems to be an optimal treatment duration.

\section{Treatment-experienced patients}

Several studies examined the role of grazoprevir-elbasvir combination therapy in treatment-experienced patients, with results showing excellent SVR rates. As with treatment-naïve patients, there was no benefit with the addition of ribavirin or extension of therapy to 18 weeks. Cirrhosis again did not significantly alter SVR. Lawitz et a $1{ }^{17}$ published data on patients who had previously failed pegylated interferon and ribavirin with or without cirrhosis. Of the 253 total patients included in their analysis, 130 patients had previously failed pegylated interferon and ribavirin. In a similar fashion to the treatmentnaïve arm, this cohort was further divided into a 12-week course $(n=65)$ and an 18 -week course $(n=65)$, with approximately half of the patients receiving ribavirin. SVR12 was achieved in $94 \%$ (30/32 patients) who underwent 12-week regimen with ribavirin, compared to $91 \%$ (30/33 patients) without ribavirin. When treated for 18 weeks, SVR12 of $100 \%$ (33/33 patients) was achieved with ribavirin, compared to $97 \%$ (31/32 patients) without ribavirin. SVR12 was achieved in $92 \%$ of patients with cirrhosis (23/25). There was no significant benefit with the addition of ribavirin or extension of therapy to 18 weeks.

Currently, there are many patients who have failed not only interferon-based therapies but also first-generation protease inhibitors. This subgroup of patients provides a unique challenge in treating $\mathrm{HCV}$. Buti et $\mathrm{al}^{20}$ and Forns et $\mathrm{al}^{21}$ reported data on a study focusing on $\mathrm{HCV}$ patients who had previously failed pegylated interferon and first-generation protease inhibitors with ribavirin. The C-SALVAGE trial was an open-label, Phase II study using a 12-week course of grazoprevir plus elbasvir and ribavirin in patients with genotype 1 infection. Both cirrhotic and noncirrhotic patients were included. A total of 79 patients were enrolled in the study with the primary endpoint being evaluation of SVR12 and also SVR24. SVR12 was 96.2\% (76/79 patients) with no further relapses at 24 weeks posttreatment. All three patients with virologic failure relapsed prior to 8 weeks posttreatment. Patients with cirrhosis had SVR12 of $94.1 \%$ (32/34 patients).

\section{Advanced chronic kidney disease}

Treatment of HCV in patients with advanced chronic kidney disease represents a major unmet need in hepatology. ${ }^{22}$ Roth et $\mathrm{al}^{23}$ reported data from the C-SURFER study, a randomized, placebo-controlled, Phase III study on the efficacy of grazoprevir and elbasvir in treatment-naïve and treatment-experienced patients with $\mathrm{HCV}$ genotype 1 infection and chronic kidney disease stage 4-5. A total of 224 patients were included in the study; 111 were assigned to the treatment group and 113 to the placebo group. An additional nonrandomized group of eleven patients underwent intensive pharmacokinetic sampling on grazoprevir and elbasvir regimen. Of the total 122 patients receiving the study drug, 116 reached the end of treatment. Six patients discontinued therapy for reasons other than virologic failure. Excluding these patients, SVR12 was achieved in 99\% (115/116) of patients. Placebo reached SVR4 of $<1 \%$ (1/113), with the one responder later identified as receiving the study drug incorrectly. Subgroup analysis showed excellent SVR12 in all groups receiving the study drug. Patients on hemodialysis achieved an SVR12 of $98.9 \%$ (86/87 patients), compared to $100 \%$ (29/29 patients) not on hemodialysis. Patients with stage 4 chronic kidney disease achieved an SVR12 of 100\% (22/22 patients), compared to $98.9 \%(75 / 75)$ patients with stage 5 chronic kidney disease. In addition, there were no significant differences in SVR12 with cirrhosis, genotype 1a versus $1 \mathrm{~b}$, or previous treatment status.

\section{HIV coinfection}

In the USA, approximately $30 \%$ of patients with HIV are also infected with $\mathrm{HCV} .{ }^{24}$ The major clinical implication of $\mathrm{HIV} / \mathrm{HCV}$ coinfection is the faster fibrosis progression realized 
in coinfected relative to $\mathrm{HCV}$-monoinfected patients. ${ }^{25}$ As previously mentioned, Sulkowski et al ${ }^{18}$ evaluated the efficacy of grazoprevir and elbasvir with or without ribavirin in the treatment of untreated $\mathrm{HIV} / \mathrm{HCV}$ coinfected patients. A total of 59 coinfected patients underwent treatment for 12 weeks. SVR12 was 97\% (28/29 patients) in the ribavirin group and $87 \%$ (26/30 patients) in the no ribavirin group. There was no significant difference with the addition of ribavirin. No significant difference was seen in SVR12 rates in coinfected patients and monoinfected patients in this study.

Grazoprevir plus elbasvir has also been shown to be effective in HIV coinfection in non-genotype $1 \mathrm{HCV}$. Rockstroh et $\mathrm{al}^{26}$ conducted an uncontrolled, nonrandomized, open-label, single-arm, Phase III study evaluating the efficacy of grazoprevir and elbasvir in patients with untreated HCV genotype 1, 4, or 6 infection and HIV coinfection with or without cirrhosis. The C-EDGE study enrolled 218 patients, with all patients receiving grazoprevir and elbasvir for 12 weeks. SVR12 was achieved in 96\% (210/218) patients. Genotype 1a patients achieved an SVR12 of $96.5 \%$ (139/144 patients), compared to $95.5 \%$ (42/44 patients) in genotype $1 \mathrm{~b}, 96.4 \%$ (27/28 patients) in genotype 4 , and $100 \%$ (2/2 patients) in genotype 6 . All 35 patients with cirrhosis achieved SVR12.

\section{Virologic failure and resistance}

All studies evaluating the efficacy of grazoprevir and elbasvir in the treatment also assessed for the presence of resistance-associated variants (RAVs) (Tables 2 and 3). NS3 and NS5A genes were amplified using reverse transcriptasepolymerase chain reaction followed by population sequencing. One of the consistent findings of these studies was the emergence of RAVs in patients who fail to respond to antiviral therapy. For instance, Lawitz et $\mathrm{al}^{17}$ evaluated baseline HCV RNA sequences for RAVs and found that 32\%(79/248) had NS3 RAVs. The SVR12 in these patients was 92\% (73/79 patients), compared to $96 \%$ (163/169 patients) in wild-type patients $(P=0.167)$. The presence of NS5A RAVs was noted in $14 \%$ patients $(34 / 243)$. The SVR12 was $82 \%(28 / 34)$ in these patients, compared to $97 \%(203 / 209$ patients) in wild-type patients $(P<0.001)$. Eight of the ten patients with virologic failure had RAVs to NS3 or NS5A and seven did not receive ribavirin. Sulkowski et $\mathrm{al}^{18}$ reported treatment failure of $4 \%$ ( $7 / 188$ patients) in monoinfected and coinfected patients who were treated for 12 weeks with or without ribavirin. In contrast, the 8-week regimen plus ribavirin group of patients with $\mathrm{HCV}$ genotype 1a had a failure rate of $17 \%$ (5/30 patients). While there was no significant difference in virologic failure between monoinfected and HIV-coinfected patients, the authors did note that at viral loads of $>10$ million IU/mL, SVR12 for monoinfected patients was 90\% (18/20 patients) as compared to $75 \%$ (12/16 patients), suggesting a possible difference, though not statistically significant. Baseline HCV RNA sequencing showed that NS3 RAVs were present in $35 \%(75 / 216)$ patients. The SVR12 in these patients was $91 \%(68 / 75$ patients $)$, as compared to $92 \%$

Table 2 Baseline RAVs and SVRI2 of varying HCV genotypes

\begin{tabular}{|c|c|c|c|c|c|c|c|}
\hline Study & RAV & GT I & GTIa & GTIb & GT4 & GT6 & SVRI2 \\
\hline \multirow[t]{2}{*}{ Lawitz et al ${ }^{17}$} & NS3 & $79 / 248$ (32\%) & NA & NA & NA & NA & $73 / 79(92 \%)$ \\
\hline & NS5A & $34 / 243(14 \%)$ & NA & NA & NA & NA & $28 / 34(82 \%)$ \\
\hline \multirow[t]{2}{*}{ Sulkowski et al ${ }^{18}$} & NS3 & $75 / 216(35 \%)$ & NA & NA & NA & NA & $68 / 75(91 \%)$ \\
\hline & NS5A & $25 / 216(12 \%)$ & NA & NA & NA & NA & $17 / 25(68 \%)$ \\
\hline \multirow[t]{8}{*}{ Zeuzem et al ${ }^{19}$} & NS3 & NA & $86 / 151$ (57\%) & $25 / 129$ (19\%) & $7 / 18$ (39\%) & $9 / 9(100 \%)$ & GTIA: $83 / 86$ (97\%) \\
\hline & & & & & & & GTIB: $24 / 25$ (96\%) \\
\hline & & & & & & & GT4: $7 / 7$ (100\%) \\
\hline & & & & & & & GT6: 7/9 (78\%) \\
\hline & NS5A & NA & $19 / 154$ (12\%) & $18 / 130(14 \%)$ & $9 / 18(50 \%)$ & $3 / 9(33 \%)$ & GTIA: I I/I9 (58\%) \\
\hline & & & & & & & GTIB: I7/I8 (94\%) \\
\hline & & & & & & & GT4: 9/9 (100\%) \\
\hline & & & & & & & GT6: 7/9 (78\%) \\
\hline Buti et $\mathrm{al}^{20}$ and & NS3 & $34 / 78(44 \%)$ & NA & NA & NA & NA & $31 / 34(91 \%)$ \\
\hline Forns et $\mathrm{a}^{21}$ & NS5A & $8 / 79(10)$ & NA & NA & NA & NA & $6 / 8(75 \%)$ \\
\hline \multirow[t]{2}{*}{ Roth et $\mathrm{a}^{23}$} & NS3 & $36 / 112$ (32\%) & NA & NA & NA & NA & $36 / 36(100 \%)$ \\
\hline & NS5A & $17 / 115$ (15\%) & NA & NA & NA & NA & $16 / 17$ (94\%) \\
\hline \multirow[t]{4}{*}{ Rockstroh et $\mathrm{al}^{26}$} & NS3 & NA & $50 \%(69 / 139)$ & $12 \%(5 / 43)$ & NA & NA & GTIA: $66 / 69$ (96\%) \\
\hline & & & & & & & GTIB: $5 / 5$ (I00\%) \\
\hline & NS5A & NA & $10 / 140(7 \%)$ & $5 / 43(12 \%)$ & NA & NA & GTIA: 8/I0 (80\%) \\
\hline & & & & & & & GTIB: 5/5 (I00\%) \\
\hline
\end{tabular}

Abbreviations: GT, genotype; HCV, hepatitis C virus; NA, not applicable; RAV, resistance-associated variant; SVRI2, sustained virologic response I2 weeks posttreatment. 
Table 3 Emergent RAVs posttreatment in virologic failure patients

\begin{tabular}{|c|c|c|c|c|c|}
\hline Study & $\begin{array}{l}\text { RAVs in failure } \\
\text { patients (\%) }\end{array}$ & NS3 RAVs (\%) & NS5A RAVs (\%) & $\begin{array}{l}\text { Common } \\
\text { NS3 }\end{array}$ & $\begin{array}{l}\text { Common } \\
\text { NS5A }\end{array}$ \\
\hline \multirow[t]{4}{*}{ Lawitz et al ${ }^{17}$} & $9 / 10(90)$ & $7 / 9(78)$ & $9 / 9(100)$ & Y56H & M28T \\
\hline & & & & Al56T/G/V & Q30L/R \\
\hline & & & & $\mathrm{DI} 68 \mathrm{~A} / \mathrm{Y}$ & L3IM \\
\hline & & & & & $\mathrm{Y} 93 \mathrm{H} / \mathrm{N}$ \\
\hline \multirow[t]{3}{*}{ Sulkowski et al ${ }^{18}$} & $10 / 12(83)$ & $9 / 10(90)$ & $9 / 10(90)$ & $\mathrm{Y} 56 \mathrm{H}$ & Q30R/H \\
\hline & & & & Al56T & L3IM \\
\hline & & & & $\mathrm{DI} 68 \mathrm{~A} / \mathrm{N}$ & Y93H/N \\
\hline \multirow[t]{4}{*}{ Zeuzem et al ${ }^{19}$} & $13 / 13(100)$ & $9 / 13$ & $13 / 13(100)$ & Y56H & M28V/A/G \\
\hline & & & & DI68A & $\mathrm{Q} 30 \mathrm{H} / \mathrm{L} / \mathrm{R}$ \\
\hline & & & & Q80K & L3IM \\
\hline & & & & & $\mathrm{Y93H}$ \\
\hline \multirow[t]{3}{*}{ Buti et $\mathrm{a}^{20}$ and Forns et $\mathrm{a}^{21}$} & $3 / 3(100)$ & $3 / 3(100)$ & $2 / 3(67)$ & DI68N & $\mathrm{Y93H}$ \\
\hline & & & & Q80K & $\mathrm{Q} 30 \mathrm{H}$ \\
\hline & & & & Al56T/A & L3IM \\
\hline \multirow[t]{4}{*}{ Rockstroh et al ${ }^{26}$} & $3 / 7(43)$ & 2/7 (29) & $4 / 7(57)$ & Q80K & Q30K \\
\hline & & & & DI68A & Y93S \\
\hline & & & & & L3IM \\
\hline & & & & & L28S \\
\hline
\end{tabular}

Abbreviation: RAV, resistance-associated variant.

(130/141 patients) with wild-type NS3 ( $P=0.698)$. NS5A RAVs were found in $12 \%$ (25/216 patients) patients. Only $68 \%(17 / 25)$ patients in this group achieved SVR12, as compared to $95 \%$ (181/191 patients) with wild-type NS5A $(P \leq 0.001)$.

Differences in baseline RAVs were noted when comparing different $\mathrm{HCV}$ genotype subtypes. Baseline NS3 RAVs are more common than NS5A RAVs. In general, genotype $1 \mathrm{~b}$ patients had lower incidence of NS3 RAVs at baseline, compared to genotype 1a patients (Table 2). Baseline NS5A RAV rates are similar for both genotype $1 \mathrm{a}$ and $1 \mathrm{~b}$ patients. Patients with NS3 RAVs achieve SVR12 at a higher rate than patients with baseline NS5A RAVs (Table 2). For example, Zeuzem et a ${ }^{19}$ reported that baseline HCV RNA sequencing detected NS3 RAVs at baseline in 86/151 (57\%) patients with genotype 1a and 25/129 (19\%) patients with genotype 1b. SVR12 was achieved in 97\% (83/86) genotype 1a patients with NS3 RAVs, compared to $89 \%$ (58/65) patients without RAVs. In genotype $1 \mathrm{~b}$ patients, SVR12 was achieved in 96\% (24/25) patients with NS3 RAVs and 100\% (104/104) patients without RAVs. NS5A RAVs were found in 19/154 (12\%) patients with genotype 1a and 18/130 (14\%) patients with genotype $1 \mathrm{~b}$. At the conclusion of the study, SVR12 was achieved in 58\% (11/19) of genotype 1a patients with NS5A RAVs, compared to $99 \%$ (133/135) without RAVs. Among genotype $1 \mathrm{~b}$ patients, SVR12 was achieved in $94 \%$ (17/18) patients with NS5A RAVs and 100\% (112/112) patients without RAVs. Among genotype 4 patients, NS3 RAVs were present in 39\% (7/18), NS5A RAVs in 50\%
(9/18), and both were present in $11 \%(2 / 18)$ patients. All these patients achieved SVR12. All genotype 6 patients had NS3 RAVs and 3/9 (33\%) had NS5A RAVs with SVR12 of $78 \%$ (7/9 patients) having been achieved in this group. The virologic failure rate was $4 \%$ (13 patients). At the time of virologic failure, NS3 RAVs were detected in 6/10, NS5A in $10 / 10$, and both in $6 / 10$ patients.

In the chronic kidney disease population, Roth et $\mathrm{a}^{23}$ reported only one virologic failure. The patient had chronic cirrhosis with genotype $1 \mathrm{~b}$ infection and stage 5 chronic kidney disease with relapse 12 weeks after the end of treatment. Baseline NS3 or NS5A RAVs were detected in 32.1\% (36/112) and 14.8\% (17/115) patients, respectively. SVR was achieved in all patients with NS3 RAVs, and an SVR12 of 94.1\% (16/17) was achieved in patients with NS5A RAVs.

When looking at HIV-coinfected patients, baseline NS3 and NS5A RAVs were found at similar rates. These patients also achieved SVR12 at similar rates to those of monoinfected HCV patients. Rockstroh et $\mathrm{al}^{26}$ found that baseline NS3 RAVs were present in 50\% (69/139) patients with HCV genotype $1 \mathrm{a}$ and $12 \%(5 / 43)$ patients with genotype $1 \mathrm{~b}$. Patients with NS3 RAVs and genotype 1a achieved an SVR12 of $96 \%$ (66/69), compared to $97 \%$ (68/70) achieved with wild-type NS3. Patients with NS3 RAVs and genotype $1 \mathrm{~b}$ achieved an SVR12 of $100 \%$ (5/5), compared to $97 \%$ (37/38) achieved with wild-type NS3. Baseline NS5A RAVs were found in $8 \%(15 / 183)$ patients with HCV genotype 1. These patients achieved an SVR12 of 87\%, as compared to 98\% (164/168) achieved in patients without NS5A RAVs. 
Of the eight virologic failures in this study, four were of genotype 1a and were assessed for treatment-emergent mutations. Two patients developed mutations in the NS3 region, while three had mutations in the NS5A region. One virologic failure patient was genotype 4 and had developed only an NS5A mutation.

In patients who had previously failed pegylated interferon, ribavirin, and first-generation protease inhibitors, Buti et $\mathrm{al}^{20}$ and Forns et $\mathrm{al}^{21}$ reported three (3.8\%) virologic failures. All three virologic failures in this study had NS3 RAVs at baseline and two had NS5A RAVs. At baseline, $43.6 \%(34 / 78)$ had NS3 variants resistant to boceprevir, telaprevir, or simeprevir. An SVR12 of 91.2\% (31/34 patients) was achieved in this group, compared to $100 \%$ (44/44) in patients without NS3 RAVs. NS5A RAVs were found in $10.1 \%(8 / 79)$ patients. SVR12 was achieved in six of these eight patients $(75 \%)$.

\section{Adverse events}

Grazoprevir plus elbasvir regimen is generally well tolerated. Although drug-related adverse events may be common, serious events are infrequent. In treatment-naïve patients, Lawitz et $\mathrm{al}^{17}$ reported that of the 253 patients included in their study, 159 (63\%) had a drug-related adverse event. The most common side effects reported were fatigue, headache, and asthenia. Serious adverse events occurred in seven (3\%) of the patients, with three ( $1 \%$ ) patients discontinuing treatment because of adverse events. Subgroup analysis showed higher rates of drug-related adverse events in patients given ribavirin, with $71 \%$ of patients having drug-related adverse events as compared to $54 \%$ in patients who did not receive ribavirin. All three patients who had discontinued therapy were in the ribavirin group. Sulkowski et al ${ }^{18}$ reported a drug-related adverse event rate of 56\% (123/218 patients). Common adverse events included fatigue, headache, nausea, and diarrhea. Three (1\%) serious adverse events were noted (one case of nausea, one case of asthenia related to the study drug, and a case of staphylococcal infection not related to the study drug). No patients died or discontinued treatment due to adverse events. Frequency of drug-related adverse events was higher (63\%) in patients who received ribavirin (90/144 patients), compared to $45 \%$ (33/74 patients) in patients who did not receive ribavirin.

Two studies compared the safety profile of grazoprevir and elbasvir to that of placebo. Zeuzem et $\mathrm{al}^{19}$ reported similar safety profiles of grazoprevir and elbasvir to that of their placebo group in treatment-naïve patients. In the active treatment group, drug-related adverse events were documented as $36.1 \%$ (114/316), compared to $39 \%$ $(41 / 105)$ in the placebo group. The most common adverse events in the active treatment group were headache (17\%), fatigue (15\%), and nausea ( $9 \%)$. Treatment was discontinued in three $(0.9 \%)$ treatment arm patients; two patients stopped at week 8 and 12 due to elevated aminotransferase levels and one due to palpitation and anxiety on day 4 of treatment. Aminotransferase levels resolved rapidly after cessation of the study drug and SV12 was achieved in both patients. Two patients in the treatment group died, but neither was considered drug related. In patients with end-stage renal disease, Roth et $\mathrm{al}^{23}$ also reported similar safety profiles between grazoprevir and elbasvir, and placebo. Adverse event rate for study drug group was $76 \%$, compared to $84 \%$ in the placebo group. The most common adverse events were headache, nausea, and fatigue, and were similar in both treatment and placebo groups. A total of $16(14 \%)$ patients in the immediate treatment group reported serious side effects, compared to $19(17 \%)$ in the placebo group. None of the serious adverse events were considered drug related. The authors reported that the frequencies and severities of liver function measures were comparable between the treatment and placebo groups. Frequencies of renal system adverse events were also comparable between both groups. Two patients in the treatment group had hemodialysis initiated during the study. Worsening chronic kidney disease stage was noted in four patients receiving the study drug, compared to two patients receiving placebo. There were no discontinuations due to drug-related adverse events in the treatment group. One patient died in the treatment group, which was not considered drug related.

Drug-related adverse events were similar in the HIVcoinfected population. Rockstroh et $\mathrm{al}^{26}$ reported an adverse event rate of $74 \%$ (161/218). Of this, 34\% (75/218) was considered to be drug-related adverse event. As with previous studies, the most common adverse events were fatigue (13\%), headache $(12 \%)$, and nausea $(9 \%)$. Six patients experienced serious adverse events, none of which were thought to be drug related. No patients discontinued treatment due to adverse events. Four patients had increased concentrations of hepatic enzymes during treatment, all of which normalized without the need for discontinuation of the study drug.

\section{Drug-drug interactions}

Grazoprevir is an inhibitor of $\mathrm{HCV}$ NS3/4A protease, an essential component of viral replication that functions in proteolytic cleavage of the $\mathrm{HCV}$-encoded polyprotein. ${ }^{27}$ It is a cytochrome P450(CYP)3A4 and P-glycoprotein substrate 
Table 4 Potential serious drug-drug interactions with grazoprevir and elbasvir

\begin{tabular}{|c|c|}
\hline Drug & Grazoprevir and elbasvir \\
\hline Atzanavir/ritonavir ${ }^{30,31}$ & $\begin{array}{l}\text { Increased levels of all drugs, } \\
\text { coadministration not recommended }\end{array}$ \\
\hline Darunavir/ritonavir ${ }^{30}$ & $\begin{array}{l}\text { Increased levels of grazoprevir and elbasvir, } \\
\text { coadministration is not recommended }\end{array}$ \\
\hline Efavirenz $z^{28,29}$ & $\begin{array}{l}\text { Decreased levels of grazoprevir and } \\
\text { elbasvir, coadministration may lead to } \\
\text { subtherapeutic levels of grazoprevir }\end{array}$ \\
\hline Lopinavir/ritonavir ${ }^{30}$ & $\begin{array}{l}\text { Increased levels of grazoprevir and elbasvir, } \\
\text { coadministration is not recommended }\end{array}$ \\
\hline Rosuvastatin ${ }^{34}$ & $\begin{array}{l}\text { Increased levels of rosuvastatin, avoid } \\
\text { coadministration }\end{array}$ \\
\hline Rifampin $^{32}$ & $\begin{array}{l}\text { Increased levels of grazoprevir and elbasvir, } \\
\text { coadministration is not recommended }\end{array}$ \\
\hline
\end{tabular}

and an inhibitor of CYP2C8, a weak inhibitor of 3A4 and UGTA1, and possible inhibitor of BCRP. Elbasvir is an inhibitor of HCV NS5A, which plays an important role in viral RNA replication and virion assembly. It is a CYP3A, P-gp substrate, and the organic anion-transporting polypeptide in vitro.

There have been several drug-drug interactions that have been studied (Table 4). Drugs that induce CYP3A4, such as efavirenz, have been shown to decrease the levels of grazoprevir and elbasvir. ${ }^{28,29}$ Drugs that inhibit CYP3A4 and organic anion-transporting polypeptide, such as lopinavir/ ritonavir and rifampin, have shown to increase the levels of grazoprevir and elbasvir. ${ }^{30-32}$ The 3-hydroxy-3-methylglutaryl-CoA reductase inhibitor levels were increased in the presence of grazoprevir and elbasvir. This may be secondary to BCRP inhibition and CYP3A4 inhibition. Levels of both atorvastatin and pitavastatin were increased with coadministration, but this was not considered clinically significant. ${ }^{33}$ However, rosuvastatin, in particular, had significantly increased levels and providers may wish to avoid coadministration. ${ }^{34}$

\section{Current approval}

The combination of grazoprevir and elbasvir was recently approved by the US Food and Drug Administration (FDA) for the treatment of hepatitis $\mathrm{C}$ genotype 1 between 12 and 16 weeks and with and without ribavirin, depending on the genotype subtype, presence of NS5A polymorphisms, and type of previous experience. ${ }^{35}$ Grazoprevir and elbasvir with and without ribavirin was also approved for patients infected with genotype 4. Of note, the FDA warns that grazoprevir and elbasvir can cause elevation of liver enzymes to greater than five times the upper limit of normal. This was seen in approximately $1 \%$ of clinical trial patients. The FDA recommends that liver-related blood tests should be performed prior to starting therapy and at certain times during treatment. As discussed, elevated aminotransferase levels were typically seen at or after treatment week 8 . The FDA further cautioned against the use of grazoprevir and elbasvir in patients with moderate or severe liver impairment.

\section{Future}

Although genotype 3 was not evaluated in the earlierreviewed trials, recent data from the C-SWIFT trial using grazoprevir, elbasvir, and sofosbuvir to treat genotype 3 patients have shown excellent results with $100 \%(14 / 14)$ noncirrhotic patients and 91\% (10/11) cirrhotic patients achieving SVR12. ${ }^{36}$ Furthermore, data from an integrated analysis of treatment-experienced patients from Phase II and III trials showed several predictors of response to grazoprevir and elbasvir. ${ }^{37}$ Among genotype 1a patients, noncirrhotics and females tended to have higher SVR12 rates. The addition of ribavirin and/or longer duration had a positive impact on SVR12, though the individual studies found no significant differences. Further studies need to be conducted to elucidate the benefits of ribavirin and longer treatment durations. Baseline NS5A RAVs had a modest negative impact on SVR12. No potential predictors were identified for genotype $1 \mathrm{~b}$ patients.

\section{Conclusion}

Studies have shown that across many subgroups, grazoprevirelbasvir combination has high efficacy in the treatment of HCV. High SVR12 rates were achieved regardless of the baseline factors such as genotype, cirrhosis, previous treatment failure, HIV coinfection, and renal failure. Studies comparing 12 -week treatment regimens to 18 -week regimens have concluded that there is no significant difference in SVR12 of the treatment regimens. Furthermore, data from currently published studies do not show a significant increase in SVR12 with the addition of ribavirin and, in fact, it has been shown to increase adverse events. Several studies have shown that ribavirin-free grazoprevir and elbasvir regimens have a good safety profile, with some studies showing no difference in adverse events when compared to placebo.

\section{Disclosure}

SS is a consultant and on the speaker bureau for Merck. The authors report no conflicts of interest in this work. 


\section{References}

1. Chak E, Talal AH, Sherman KE, Schiff ER, Saab S. Hepatitis C virus infection in USA: an estimate of true prevalence. Liver Int. 2011; 31(8):1090-1101.

2. Davis GL, Alter MJ, El-Serag H, Poynard T, Jennings LW. Aging of hepatitis C virus (HCV)-infected persons in the United States: a multiple cohort model of HCV prevalence and disease progression. Gastroenterology. 2010;138(2):513-521, 521.e511-516.

3. Razavi H, Elkhoury AC, Elbasha E, et al. Chronic hepatitis C virus (HCV) disease burden and cost in the United States. Hepatology. 2013; 57(6):2164-2170.

4. Manns MP, McHutchison JG, Gordon SC, et al. Peginterferon alfa- $2 b$ plus ribavirin compared with interferon alfa- $2 b$ plus ribavirin for initial treatment of chronic hepatitis C: a randomised trial. Lancet. 2001;358(9286):958-965

5. Nicot F, Alric L, Barange K, et al. Influence of HCV genotype 1 subtypes on the virus response to PEG interferon alpha-2a plus ribavirin therapy. J Med Virol. 2011;83(3):437-444.

6. Fried MW, Shiffman ML, Reddy KR, et al. Peginterferon alfa-2a plus ribavirin for chronic hepatitis $\mathrm{C}$ virus infection. $N$ Engl J Med. 2002; 347(13):975-982.

7. Saab S, Jackson C, Nieto J, Francois F. Hepatitis C in African Americans. Am J Gastroenterol. 2014;109(10):1576-1584; quiz 1575, 1585.

8. Saab S, Rheem J, Sundaram V. Hepatitis C infection in the elderly. Dig Dis Sci. 2015;60(11):3170-3180.

9. Kim AI, Dorn A, Bouajram R, Saab S. The treatment of chronic hepatitis C in HIV-infected patients: a meta-analysis. HIV Med. 2007; 8(5):312-321.

10. Ghany MG, Liang TJ. Current and future therapies for hepatitis $\mathrm{C}$ virus infection. N Engl J Med. 2013;369(7):679-680.

11. Kohli A, Shaffer A, Sherman A, Kottilil S. Treatment of hepatitis C: a systematic review. JAMA. 2014;312(6):631-640.

12. Pearlman BL, Traub N. Sustained virologic response to antiviral therapy for chronic hepatitis $\mathrm{C}$ virus infection: a cure and so much more. Clin Infect Dis. 2011;52(7):889-900.

13. Bruno S, Stroffolini T, Colombo M, et al. Sustained virological response to interferon-alpha is associated with improved outcome in HCV-related cirrhosis: a retrospective study. Hepatology. 2007;45(3): 579-587.

14. Singal AK, Singh A, Jaganmohan S, et al. Antiviral therapy reduces risk of hepatocellular carcinoma in patients with hepatitis $\mathrm{C}$ virus-related cirrhosis. Clin Gastroenterol Hepatol. 2010;8(2):192-199.

15. van der Meer AJ, Veldt BJ, Feld JJ, et al. Association between sustained virological response and all-cause mortality among patients with chronic hepatitis $\mathrm{C}$ and advanced hepatic fibrosis. JAMA. 2012; 308(24):2584-2593.

16. Younossi ZM, Kanwal F, Saab S, et al. The impact of hepatitis $\mathrm{C}$ burden: an evidence-based approach. Aliment Pharmacol Ther. 2014;39(5): $518-531$.

17. Lawitz E, Gane E, Pearlman B, et al. Efficacy and safety of 12 weeks versus 18 weeks of treatment with grazoprevir (MK-5172) and elbasvir (MK-8742) with or without ribavirin for hepatitis C virus genotype 1 infection in previously untreated patients with cirrhosis and patients with previous null response with or without cirrhosis (C-WORTHY): a randomised, open-label phase 2 trial. Lancet. 2015;385(9973):1075-1086.

18. Sulkowski M, Hezode C, Gerstoft J, et al. Efficacy and safety of 8 weeks versus 12 weeks of treatment with grazoprevir (MK-5172) and elbasvir (MK-8742) with or without ribavirin in patients with hepatitis $C$ virus genotype 1 mono-infection and HIV/hepatitis $C$ virus co-infection (C-WORTHY): a randomised, open-label phase 2 trial. Lancet. 2015;385(9973):1087-1097.

19. Zeuzem S, Ghalib R, Reddy KR, et al. Grazoprevir-elbasvir combination therapy for treatment-naive cirrhotic and noncirrhotic patients with chronic hepatitis $\mathrm{C}$ virus genotype 1, 4, or 6 infection: a randomized trial. Ann Intern Med. 2015;163(1):1-13.
20. Buti M, Gordon SC, Zuckerman E, et al. Grazoprevir, elbasvir, and ribavirin for chronic hepatitis $\mathrm{C}$ virus genotype 1 infection after failure of pegylated interferon and ribavirin with an earlier-generation protease inhibitor: final 24-week results from C-SALVAGE. Clin Infect Dis. 2016;62(1):32-36.

21. Forns X, Gordon SC, Zuckerman E, et al. Grazoprevir and elbasvir plus ribavirin for chronic HCV genotype-1 infection after failure of combination therapy containing a direct-acting antiviral agent. $J$ Hepatol. 2015;63(3):564-572.

22. Maruyama A, Partovi N, Yoshida EM, Erb SR, Azalgara VM, Hussaini T. A review of direct-acting antivirals for the treatment of hepatitis $\mathrm{C}$ in patients with advanced chronic kidney disease. Nephrol Dial Transplant. Epub 2015 Oct 19.

23. Roth D, Nelson DR, Bruchfeld A, et al. Grazoprevir plus elbasvir in treatment-naive and treatment-experienced patients with hepatitis $\mathrm{C}$ virus genotype 1 infection and stage 4-5 chronic kidney disease (the C-SURFER study): a combination phase 3 study. Lancet. 2015; 386(10003):1537-1545

24. Lacombe K, Rockstroh J. HIV and viral hepatitis coinfections: advances and challenges. Gut. 2012;61 Suppl 1:i47-i58.

25. Joshi D, O'Grady J, Dieterich D, Gazzard B, Agarwal K. Increasing burden of liver disease in patients with HIV infection. Lancet. 2011; 377(9772):1198-1209.

26. Rockstroh JK, Nelson M, Katlama C, et al. Efficacy and safety of grazoprevir (MK-5172) and elbasvir (MK-8742) in patients with hepatitis $\mathrm{C}$ virus and HIV co-infection (C-EDGE CO-INFECTION): a nonrandomised, open-label trial. Lancet HIV. 2015;2(8):e319-e327.

27. Yeh W, Fraser IP, Reitmann C, et al. Pharmacokinetic interaction of HCV protease inhibitor MK5172 and ritonavir in healthy subjects [abstract 52]. In: HEPDART 2013: Frontiers in Drug Development for Viral Hepatitis; December 8-12, 2013; Big Island, HI.

28. Talaty JE, Caro L, Yeh W, et al. Pharmacokinetic interaction between the HCV protease inhibitor MK-5172 and efavirenz in normal healthy volunteers [abstract 492]. In: 64th Annual Meeting of the American Association for the Study of Liver Diseases (AASLD); November 1-5, 2013; Washington, DC.

29. Yeh W, Marshall W, Mangin E, et al. Pharmacokinetic interactions between the HCV NS5A inhibitor MK-8742 and efavirenz [abstract 498]. In: Conference on Retroviruses and Opportunistic Infections (CROI); March 3-6, 2014; Boston, MA.

30. Caro L, Talaty JE, Guo Z, et al. Pharmacokinetic interactions between the HCV protease inhibitor MK-5172 and ritonavir-boosted HIV protease inhibitors (atazanavir, lopinavir, darunavir) in healthy volunteers [abstract 487]. In: 64th Annual Meeting of the American Association for the Study of Liver Diseases (AASLD); November 1-5, 2013; Washington, DC.

31. Yeh WY, Marshall W, Ma J, et al. Ritonavir-boosted atazanavir, lopinavir, \& darunavir increase HCV NS5A inhibitor MK-8742 levels [abstract 635]. In: Conference on Retroviruses and Opportunistic Infections (CROI); March 3-6, 2014; Seattle, WA.

32. Caro L, Talaty JE, Guo Z, et al. Pharmacokinetic interaction between the HCV protease inhibitor MK-5172 and IV and oral rifampin in healthy volunteers [abstract 495]. In: 64th Annual Meeting of the American Association for the Study of Liver Diseases (AASLD); November 1-5, 2013; Washington, DC.

33. Caro L, Talaty JE, Guo Z, et al. Pharmacokinetic interaction between the HCV protease inhibitor MK-5172 and midazolam, pitavastatin, and atorvastatin in healthy volunteers [abstract 477]. Hepatology. 2013;58(4):437A

34. Caro L, Marshall WL, Feng HP, et al. Coadministration of HCV protease inhibitor grazoprevir with HCV NS5A inhibitor elbasvir has no effect on pravastatin but increases rosuvastatin exposure in healthy subjects [abstract 17]. In: 16th International Workshop on Clinical Pharmacology of HIV \& Hepatitis Therapy; May 26-28, 2015; Washington, DC.

35. Package Insert. ZepatierTM (elbasvir and grazoprevir). Food and Drug Administration. 2016 
36. Poordad F, Lawitz E, Gutierrez J, et al. C-swift: Grazoprevir/ elbasvir + sofosbuvir in cirrhotic and noncirrhotic, treatment-naive patients with hepatitis c virus genotype 1 infection, for durations of 4 , 6 or 8 weeks and genotype 3 infection for durations of 8 or 12 weeks. In: 50th Annual Meeting of the European Association for the Study of the Liver; April 22-26, 2015; Vienna, Austria.
37. Zeuzem S, Rockstroh JK, Kwo PY, et al. Predictors of response to elbasvir/grazoprevir among HCV genotype 1 (GT1)-infected patients: Integrated analysis of phase 2-3 trials [abstract 700]. In: 66th Annual Scientific Congress of the American Association for the Study of Liver Diseases (AASLD); November 12-17, 2015; San Francisco, CA.

\section{Publish your work in this journal}

Drug Design, Development and Therapy is an international, peerreviewed open-access journal that spans the spectrum of drug design and development through to clinical applications. Clinical outcomes, patient safety, and programs for the development and effective, safe, and sustained use of medicines are a feature of the journal, which has also been accepted for indexing on PubMed Central. The manuscript management system is completely online and includes a very quick and fair peer-review system, which is all easy to use. Visit http://www.dovepress.com/testimonials.php to read real quotes from published authors.

Submit your manuscript here: http://www.dovepress.com/drug-design-development-and-therapy-journal 